\title{
Analisis Pengaruh Koefisien Watermarking pada Citra RGB dengan Menggunakan Perbandingan DCT dan DWT
}

\section{Analysis of the Effect of Watermarking Coefficients on RGB Images Using the DCT-DWT Comparison}

\author{
Kholidiyah Masykuroh $^{\mathbf{1}^{*}}$ \\ ${ }^{1}$ Program Studi Teknik Telekomunikasi \\ Fakultas Teknik Telekomunikasi dan Elektro \\ Institut Teknologi Telkom Purwokerto \\ Jalan D.I. Panjaitan No. 128 \\ kholidiyah@ittelkom-pwt.ac.id ${ }^{1 *}$
}

\begin{abstract}
Abstrak - Perkembangan internet yang semakin pesat dan kemudahan akses informasi digital menjadi peluang terjadinya cybercrime. Teknik pengamanan diperlukan pada informasi yang akan dikirimkan melalui media transmisi baik wireless maupun wired. Melalui penerapan watermarking diharapkan informasi terjaga dari serangan, penyisipan, penghapusan data, dan penggantian data. Penelitian ini membahas perbandingan metode watermarking menggunakan Discrete Cosine Transform (DCT) dan Discrete Wavelet Transform (DWT) pada citra berwarna. Means Square Error (MSE) dan Peak Signal to Noise Ratio (PSNR) merupakan parameter uji untuk mengukur rasio perbandingan citra asli dan citra watermarking. Hasil pengujian menunjukkan bahwa perbedaan jenis transformasi yang digunakan mempengaruhi nilai SNR citra RGB. Citra RGB dengan menggunakan DCT memiliki nilai SNR yang lebih tinggi dibandingkan dengan DWT yang ditunjukkan dengan nilai SNR citra Peppers > $30 \mathrm{~dB}$. Nilai koefisien yang diberikan pada citra yang disisipkan bervariasi mulai dari 5, 10, dan 50. Nilai ini mempengaruhi nilai SNR citra RGB dengan transformasi DCT.
\end{abstract}

Kata Kunci: watermarking, cybercrime, DCT, MSE, PSNR.

\begin{abstract}
Along with the rapid development of the internet and the ease of access to digital information, cybercrime has a chance to occur. Security techniques are needed for information to be transmitted via transmission media, either wireless or wired. The application of watermarking has an opportunity to protect the information from attacks, insertion, deletion, and data replacement. This research discusses the comparison of watermarking methods using Discrete Cosine Transform (DCT) and Discrete Wavelet Transform (DWT) on color images. Means Square Error (MSE) and Peak Signal to Noise Ratio (PSNR) are a method to test parameters for measure the original image's ratio to the watermark image. The test results showed that the different types of transformations affect the SNR value of the RGB image. RGB image using DCT has a higher SNR value than DWT, which is indicated by the SNR value of Peppers image $>30 \mathrm{~dB}$. The coefficient value given to the inserted image varies from 5,10 , and 50 . This value affects the SNR value of RGB images with DCT transformation.
\end{abstract}

Keywords: watermarking, cybercrime, DCT, MSE, PSNR.

TELKA, Vol.7, No.1, Mei 2021, pp. 62 70

ISSN (e): 2540-9123

ISSN (p): 2502-1982 


\section{Pendahuluan}

Beberapa jenis informasi seperti teks, audio, gambar, dan video apabila disematkan dengan konten multimedia lain disebut sebagai watermarking digital. Salah satu informasi berperan sebagai embedded disebut sebagai watermark dan yang lain sebagai cover [1]. Contoh dari penerapan watermarking adalah monitoring siaran, pelacakan transaksi, otentikasi konten, galeri foto, perpustakaan digital, dan pengiriman informasi secara realtime [2].

Penelitian ini menggunakan citra sebagai embed yang disisipkan pada citra lain sebagai embedded. Adapun Discrete Cosine Transform (DCT) dipergunakan sebagai salah satu metode transformasi dari domain spasial ke domain frekuensi. Selain itu, teknik tranformasi yang dapat digunakan adalah Discrete Wavelet Transform (DWT). Penggunaan transformasi DWT bertujuan untuk melindungi citra hasil watermarking dari kegiatan ilegal, seperti perlindungan hak cipta dari duplikasi ilegal [3].

Adapun tujuan fundamental dari penerapan proteksi informasi dengan watermarking ini diantaranya: 1) kerahasiaan; 2) integritas data; dan 3) otentikasi [4][5]. Dengan penerapan watermarking diharapkan informasi terjaga dari serangan, kemungkinan terjadinya manipulasi seperti penyisipan, penghapusan data, dan penggantian data. Selain itu, dengan otentikasi informasi dapat terjaga keasliannya.

Discrete Cosine Transform (DCT) digunakan untuk mentransformasi sinyal dari domain spasial ke domain frekuensi. Sinyal domain spasial dapat direpresentasikan sebagai penjumlahan dari serangkaian gelombang kosinus berosilasi pada frekuensi yang berbeda. Ada beberapa varian dari DCT, namun varian yang paling umum digunakan adalah DCT dua dimensi atau 2D-DCT. Formulasi 2D-DCT pada Persamaan (1) dan (2) ditunjukkan sebagai berikut [6]:

$$
\begin{aligned}
c(u, v)=\frac{1}{4} \alpha(u) \alpha(v) \sum_{x=0}^{N-1} \sum_{y=0}^{N-1} f(x, y) \cos \frac{(2 x+1) \pi u}{2 N} \cos \frac{(2 y+1) \pi v}{2 N} \\
\propto(u)=\propto(v)= \begin{cases}\sqrt{\frac{1}{N}} & \text { untuk } u, v=0 \\
\sqrt{\frac{2}{N}} & \text { untuk } u, v=1,2, \ldots, N-1\end{cases}
\end{aligned}
$$

Dengan $c(u, v)$ adalah nilai piksel pada baris $u$ dan kolom $v$ pada domain spasial. Sedangkan $f(x, y)$ adalah nilai piksel pada baris $x$ dan kolom $y$ pada domain frekuensi. Dan $N$ menunjukkan ukuran baris dan kolom dari citra.

Dan invers DCT Persamaan (3) dan (4) didefinisikan sebagai berikut:

$$
\begin{aligned}
f(x, y)= & \alpha(u) \alpha(v) \sum_{u=0}^{N-1} \sum_{v=0}^{N-1} c(u, v) \cos \frac{(2 x+1) \pi u}{2 N} \cos \frac{(2 y+1) \pi v}{2 N} \\
& \propto(u)=\propto(v)= \begin{cases}\sqrt{\frac{1}{N}} & \text { untuk } u, v=0 \\
\sqrt{\frac{2}{N}} & \text { untuk } u, v=1,2, \ldots, N-1\end{cases}
\end{aligned}
$$

Dengan $f(x, y)$ adalah nilai piksel pada baris $x$ dan kolom $y$ pada domain frekuensi. Sedangkan $c(u, v)$ adalah nilai piksel pada baris $u$ dan kolom $v$ pada domain spasial. Dan $N$ menunjukkan ukuran baris dan kolom dari citra.

DCT menghasilkan koefisien frekuensi yang diberikan dari domain spasial. Pada proses DCT ukuran matriks NxM akan diperoleh ukuran matriks yang sama pada domain frekuensi. Data diubah menjadi tiga band frekuensi yaitu Low Frequency (LF), Middle Frequency (MF), High 
Frequency (HF). Dimulai dari atas sebelah kiri yang merepresentasikan frekuensi rendah, frekuensi tengah dan frekuensi tinggi seperti ditunjukkan dalam Gambar 1 [6]. Berdasarkan literatur metode watermarking dengan berbasis DCT, menggunakan koefisien dari Frekuensi Tengah (Middle Frequency).

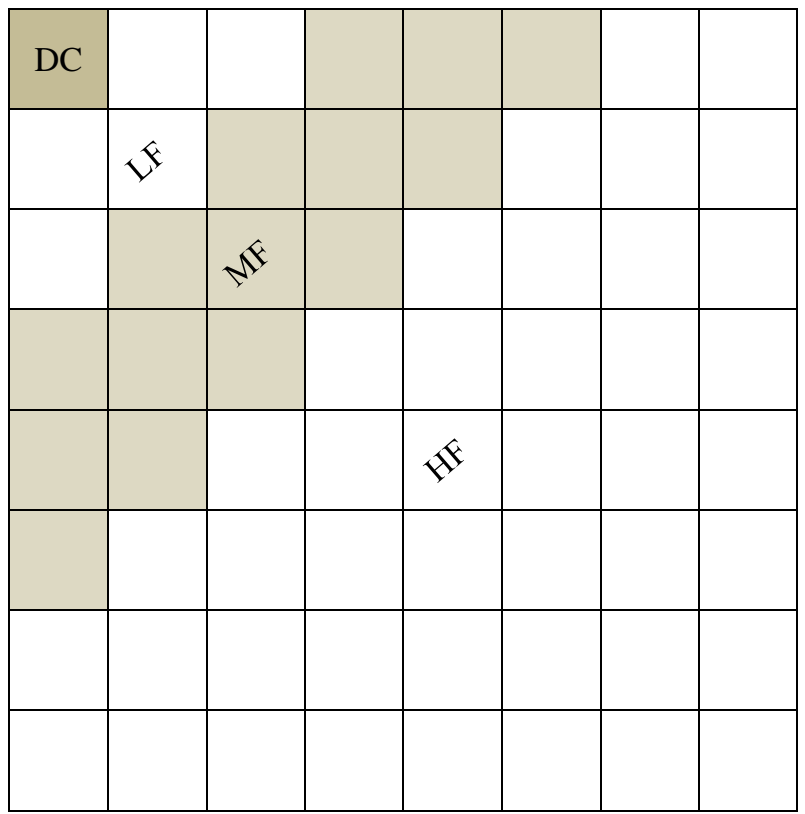

Gambar 1. Pita frekuensi DCT.

Teknik yang digunakan dalam transformasi DWT adalah dengan membagi citra menjadi empat bagian frekuensi, yaitu: satu bagian frekuensi rendah atau LL, dan tiga bagian frekuensi tinggi yang disebut HL, LH, dan $\mathrm{HH}$ [7]. Tranformasi ini memiliki rasio kompresi tinggi. Kelebihan dari transformasi ini adalah teknik ini memiliki kemampuan mengidentifikasi bagian di Gambar 2, sehingga citra dapat disisipkan dengan baik dalam bagian tersebut [8].

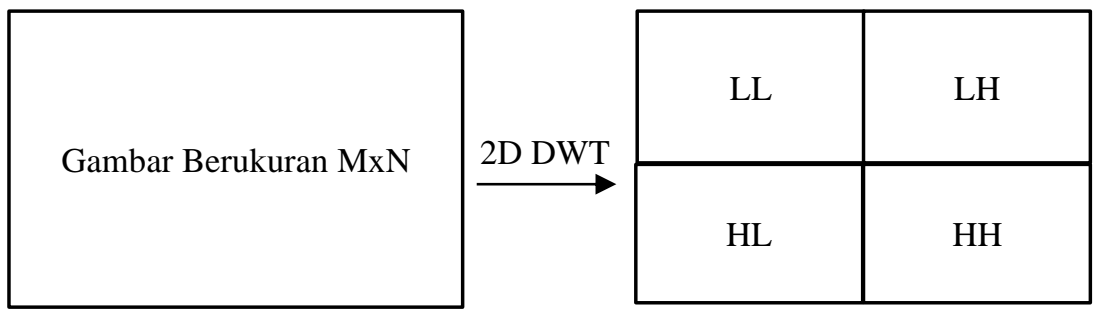

Gambar 2. Subband hasil transformasi DWT.

Peak Signal to Noise Ratio (PSNR) merupakan rasio perbandingan antara harga maksimum dari intensitas citra asli dengan citra noise, yang dinyatakan dalam satuan decibel (dB) [9]. PSNR digunakan untuk mengukur kualitas rekosntruksi dalam kompresi citra. Cara yang paling mudah untuk mendefinisikan nilainya adalah dengan menggunakan Mean Square Error (MSE) Persamaan (5), yaitu [10]:

$$
M S E=\frac{1}{m n} \sum_{i=0}^{m-1} \sum_{j=0}^{n-1}\|I(i, j)-K(i, j)\|^{2}
$$

dengan:

$m \times n$ : resolusi gambar

I : gambar hasil rekonstruksi

K : gambar asli

ISSN (e): 2540-9123

ISSN (p): 2502-1982 
Nilai PSNR Persamaan (6) diperoleh dengan perhitungan sebagai berikut:

$$
P S N R=10 \log _{10}\left(\frac{M A X_{t}^{2}}{M S E}\right)=20 \log _{10}\left(\frac{M A X_{t}}{\sqrt{M S E}}\right)
$$

$M A X_{t}$ adalah nilai maksimum piksel untuk citra yang diuji. Karena citra yang berukuran 8 bit per pixel, sehingga $M A X_{t}$ bernilai 255 .

\section{Metode Penelitian}

Metoda watermarking yang diterapkan pada penelitian ini, dijelaskan dalam Gambar 3 [8].

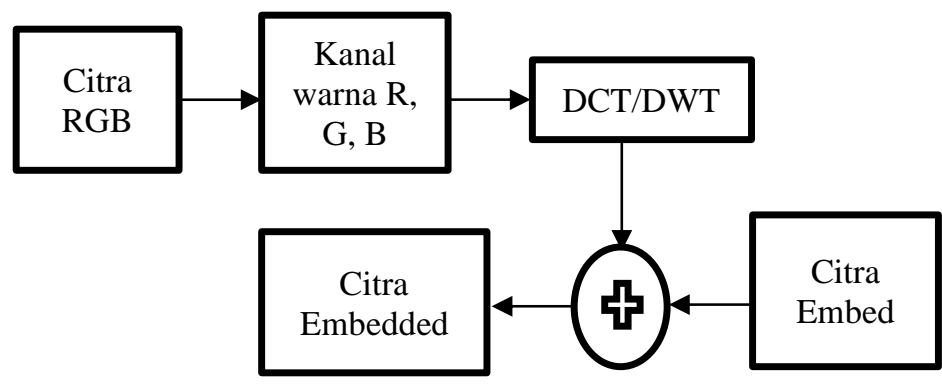

Gambar 3. Diagram proses watermarking.

\subsection{Citra RGB}

Citra RGB adalah citra informasi asli yang masih memiliki warna kombinasi Red, Green, dan Blue (RGB). Pada penelitian ini menggunakan 5 Citra RGB sebagai citra uji. Citra uji tersebut adalah Peppers, Lena, Baboon, Parkinglot, dan Viptraffic ditunjukkan pada Tabel 1.

\subsection{Kanal Warna RGB}

Citra masukan yang memiliki warna dasar RGB kemudian dipisahkan kedalam kanal warna dasarnya, yaitu Red, Green, dan Blue. Kemudian dilakukan proses pada masing-masing kanal warna tersebut. Hal ini dimaksudkan untuk mempermudah proses penggabungan dengan citra tambahan (Citra Embed). Citra RGB awalnya memiliki 3 kanal atau berdimensi 3, dipisahkan menjadi kanal warnanya masing-masing berdimensi 1 . Kanal warna berdimensi 1 akan lebih mudah dalam pengolahan citra dengan teknik watermarking. Diakhir proses watermarking, kanal warna berdimensi 1 akan dikembalikan lagi menjadi Citra RGB berdimensi 3 sebagai keluaran dari proses watermarking.

\subsection{Transformasi DCT atau DWT}

Discrete Cosines Transform (DCT) merupakan transformasi dari domain spatial ke domain frekuensi. Selain DCT, transformasi yang digunakan adalah Discrete Wavelet Tranform (DWT). Dua jenis transformasi dipilih untuk mengamati pengaruh teknik watermarking yang diterapkan pada citra RGB terhadap jenis transformasi baik DCT maupun DWT.

\subsection{Citra Embedded}

Citra Embedded adalah citra yang sudah ditambahkan dengan Citra Embed, atau disebut juga Citra Watermarking. Citra Embed yang digunakan dalam penelitian ini dihasilkan dari generator nol atau zeros. Berikut ini merupakan source code yang digunakan untuk menghasilkan Citra Embed 
$\mathrm{a}=\mathrm{zeros}(300,500)$;

a $(100: 250,100: 350)=1$;

save m.dat a -ascii

Pada proses watermarking nilai Citra Embed akan dikalikan dengan koefisien 5, 10, dan 50. Nilai koefisien ini dimaksudkan untuk mengamati perbedaan kuantitas citra yang disisipkan terhadap kualitas citra yang disisipi. Kualitas citra yang disisipkan dinaikkan nilai intensitas warnanya seiring dengan semakin besar nilai koefisien yang diberikan.

\section{Hasil dan Pembahasan}

Simulasi dibuat dengan melakukan pemrograman langsung di dalam GUI menggunakan software Matlab R2016a [11][12]. Bentuk tampilan GUI yang sudah dibuat dapat dilihat pada Gambar 4. Pada GUI Watermarking Citra menggunakan dua Axes untuk menampilkan gambar sebelum dan sesudah proses. Terdapat dua Push Button, Push Button pertama untuk memilih citra yang akan diuji dan Push Button yang kedua untuk melakukan proses pengolahan citra. Proses pengolahan citra dimulai dari penyisipan Citra Embed ke Citra Embedded, dilanjutkan dengan proses transformasi DCT atau DWT, sampai dengan pemisahan kembali antara Citra Embed dan Citra Embedded. Jenis transformasi yang digunakan dipilih dengan menggunakan Radio Button yaitu antara DCT atau DWT. Kemudian dua Edit Text, Edit Text pertama digunakan untuk memasukkan nilai koefisien dan Edit Text yang kedua untuk mendapatkan nilai SNR hasil pengujian.

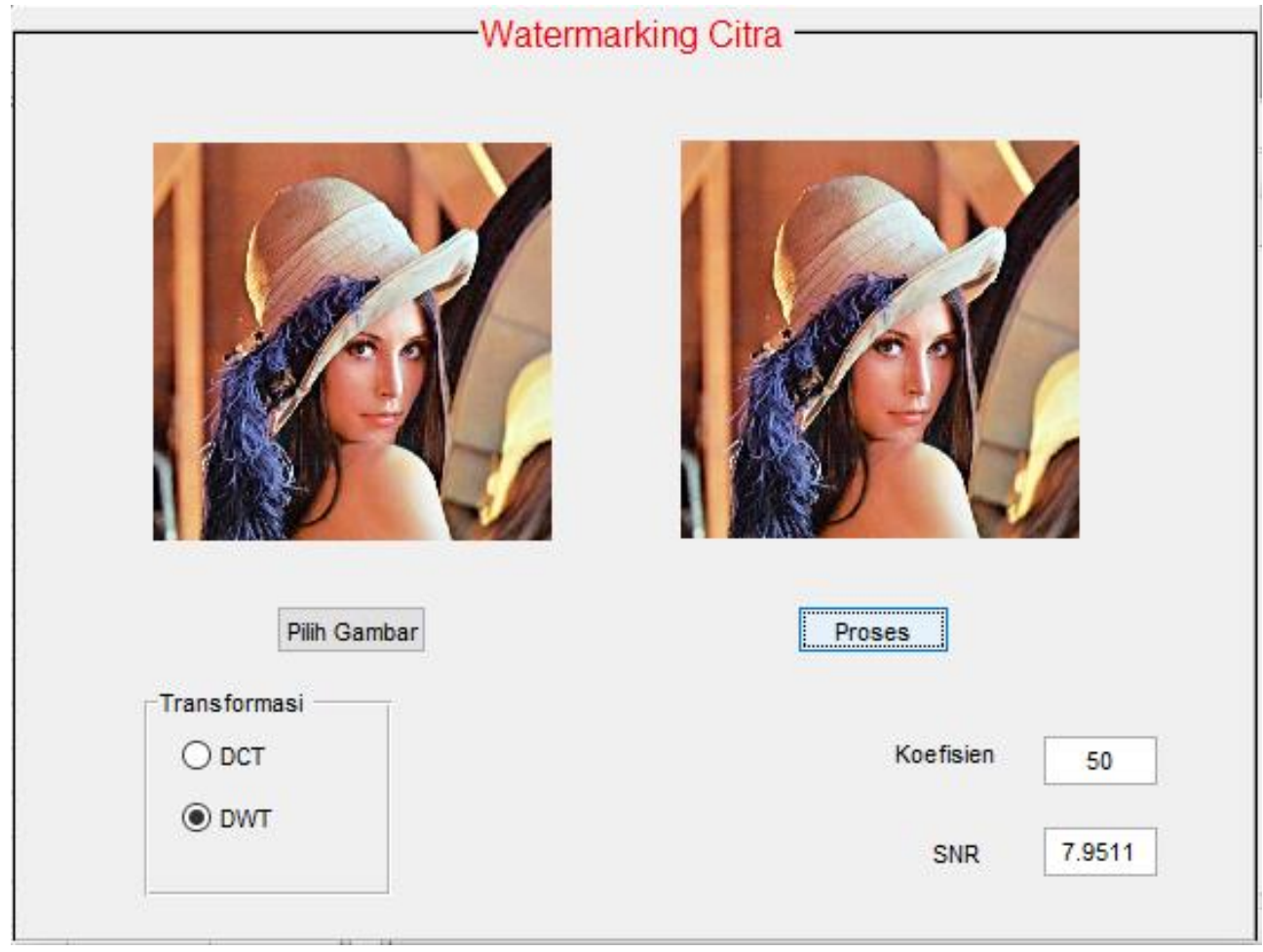

Gambar 4. GUI watermarking citra.

Pengujian dilakukan dengan menggunakan dua jenis transformasi yaitu DCT dan DWT. Citra RGB yang diuji dijelaskan dalam Tabel 1. Pengujian dilakukan dengan menghitung SNR untuk ke lima citra RGB dengan merubah nilai koefisien. Nilai koefisien ini menunjukkan semakin tingginya intensitas citra yang disisipkan dan melihat pengaruhnya pada citra yang disisipi. Semakin besar nilai koefisien maka akan meningkatkan kerusakan pada citra yang disisipi seperti ditunjukkan dalam Gambar 4. 
Langkah pertama dalam pengujian adalah menekan tombol pilih gambar, setelah itu akan muncul pilihan Citra RGB yang ingin diamati. Kemudian memilih jenis transformasi yang akan digunakan DCT atau DWT. Langkah ketiga memasukkan nilai koefisien citra yang disisipkan, penelitian ini menggunakan variasi 5, 10 dan 50. Langkah terakhir tekan tombol proses, setelah menekan tombol tersebut akan muncul nilai SNR. Nilai SNR dikumpulkan dan dibuat grafik menggunakan Microsoft Excel.

Tabel 1. Citra uji.

\begin{tabular}{|c|c|c|}
\hline No. & Nama & Citra \\
\hline 1 & Peppers.png & \\
\hline 2 & Lena.jpg & \\
\hline 3 & Baboon.png & \\
\hline 4 & Parkinglot.png & \\
\hline 5 & Viptraffic.png & \\
\hline
\end{tabular}

Nilai koefisien yang digunakan dalam pengujian mulai dari 5, 10, dan 50. Citra RGB yang diuji yaitu: Peppers, Lena, Baboon, Parkinglot, dan Viptraffic. Kelima citra uji memiliki nilai SNR yang berbeda-beda, hal ini dikarenakan karena masing-masing citra uji memiliki intensitas warna yang berbeda-beda. 


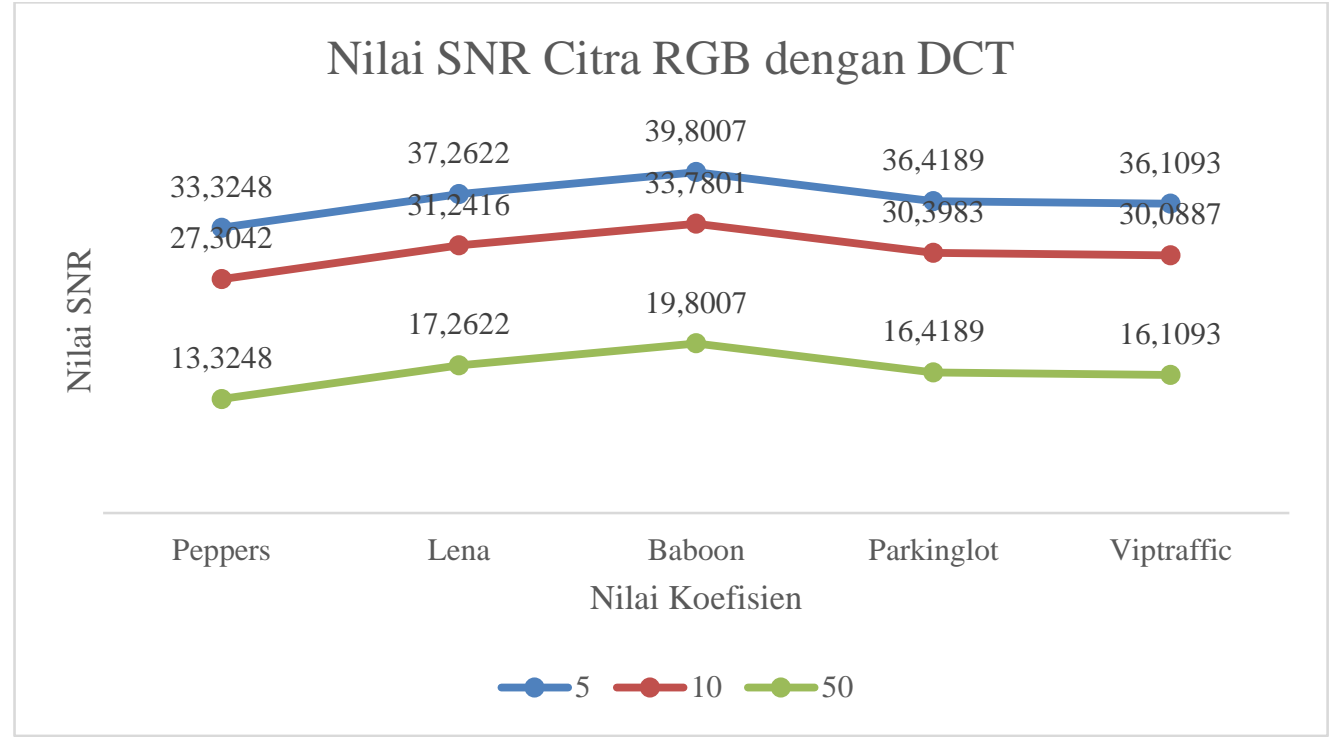

Gambar 5. Pengaruh nilai koefisien terhadap nilai SNR citra RGB dengan DCT.

Berdasarkan grafik pada Gambar 5. Citra yang memiliki SNR paling tinggi adalah Baboon. Citra ini pada saat diberikan nilai koefisien 5 memiliki nilai SNR 39,8007. Pada saat nilai koefisien 10 memiliki nilai SNR 33,7801. Dan pada saat nilai koefisien 50 memiliki nilai SNR 19,8007. Dapat disimpulkan bahwa semakin tinggi nilai koefisien menyebabkan semakin turun nilai SNR dari kelima citra uji. Hal ini karena intensitas warna dari citra yang disisipkan memperngaruhi kualitas citra yang disisipi.

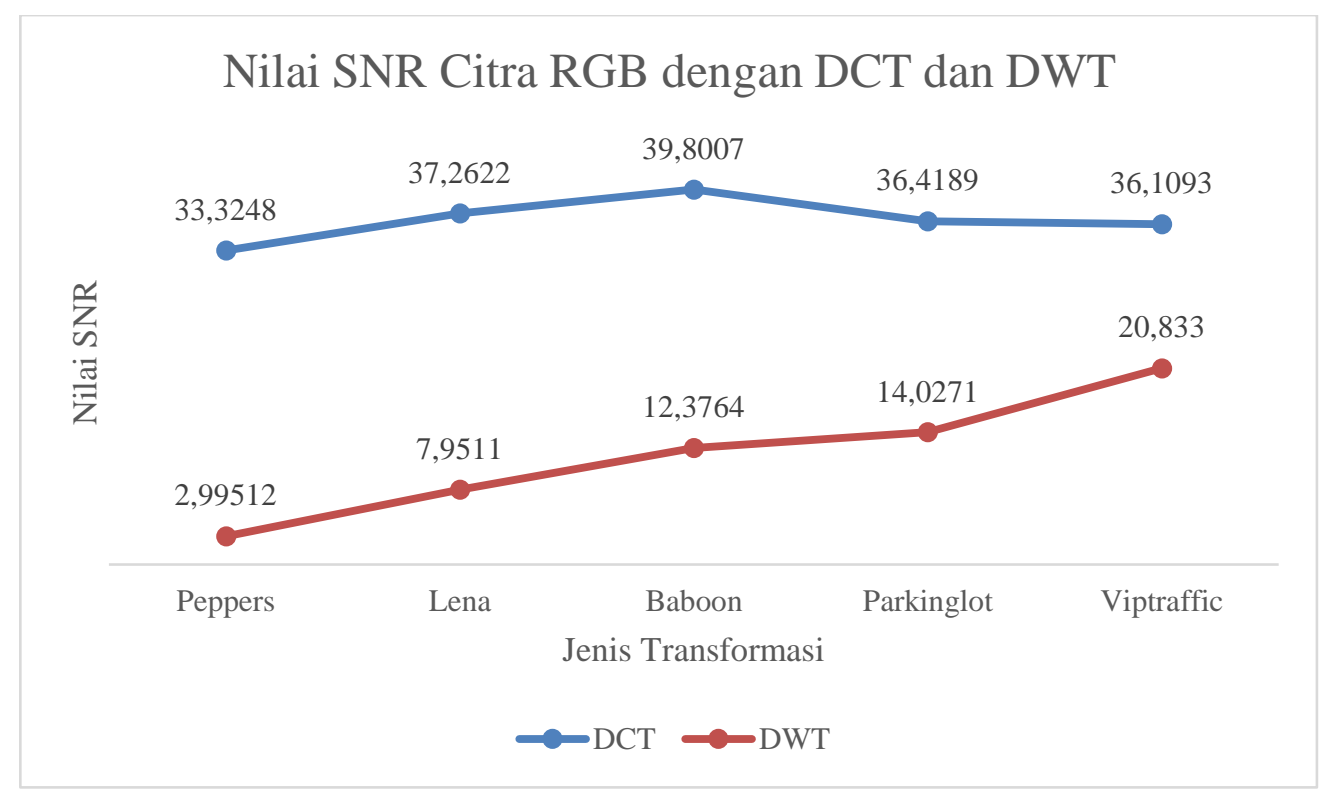

Gambar 6. Pengaruh jenis transformasi terhadap nilai SNR citra RGB.

Penelitian ini menggunakan dua jenis tranfsormasi yaitu DCT dan DWT. Gambar 6 menunjukkan pengaruh perbedaan transformasi yang digunakan. Perbedaan jenis transformasi mempengaruhi nilai SNR kelima citra uji. Citra RGB dengan DWT memiliki nilai SNR yang lebih kecil dari nilai SNR dengan DCT. Hal ini terjadi karena perbedaan teknik transformasi yang diterapkan. Sehingga dapat disimpulkan bahwa DCT merupakan transformasi yang baik untuk digunakan dalam teknik watermarking, dibandingkan dengan DWT. 


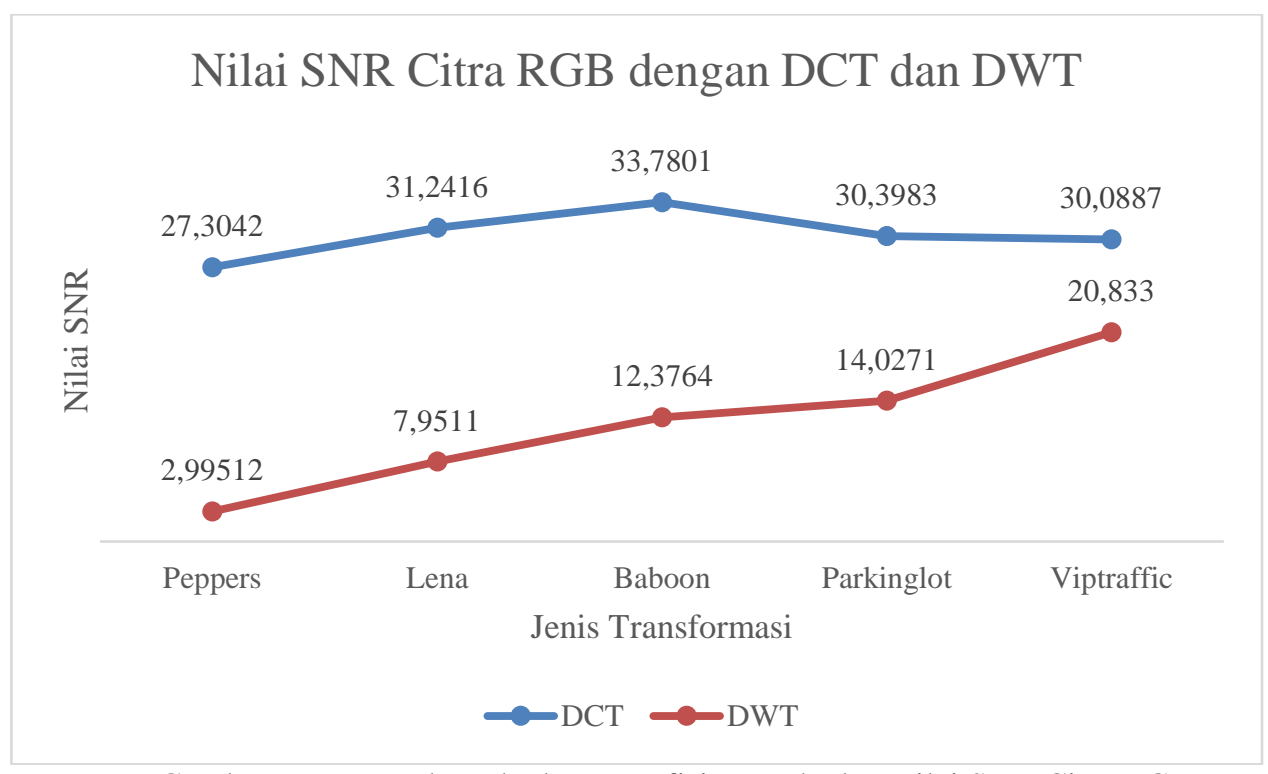

Gambar 7. Pengaruh Perbedaan Koefisien Terhadap Nilai SNR Citra RGB

Gambar 6 menunjukkan grafik nilai SNR dari citra RGB dengan koefisien 5. Sedangkan Gambar 7 menunjukkan nilai SNR dari citra RGB dengan koefisien 10. Pada citra RGB yang menerapkan tranfsormasi DCT terlihat perubahan nilai koefisien berpengaruh pada nilai SNR. Semakin tinggi koefisien maka makin menurun nilai SNR. Bagiamana dengan transformasi DWT, pada transformasi DWT perubahan nilai koefisien tidak mempengaruhi nilai SNR dari citra RGB.

\section{Kesimpulan}

Berdasarkan hasil uji lima citra RGB dengan menggunakan DCT, diperoleh hasil SNR yang bervariasi. Hal ini disebabkan karena perbedaan dari intensitas warna yang dimiliki oleh kelima citra uji tersebut berbeda-beda. Selain itu, terjadi penurunan nilai SNR apabila nilai koefisien citra yang disisipkan dinaikkan. Berdasarkan perolehan nilai SNR, dapat disimpulkan bahwa intensitas warna citra yang disisipkan dapat mempengaruhi kualitas dari citra yang disisipi. Selain DCT, transformasi yang digunakan dalam penelitian ini adalah DWT. Perbedaan jenis transformasi yang digunakan mempengaruhi nilai SNR kelima citra uji. Citra RGB dengan menggunakan DCT memiliki nilai SNR yang lebih tinggi dibandingkan dengan DWT. Sedangkan nilai koefisien yang bervariasi tidak mempengaruhi citra RGB dengan transformasi DWT. Dari hasil pengujian, diperoleh bahwa DCT merupakan jenis transformasi yang baik untuk digunakan dalam teknik watermarking dibandingkan dengan DWT. Hal ini ditunjukkan dengan nilai SNR yang lebih tinggi.

\section{Referensi}

[1] R. Munir, "Steganografi dan Watermarking Departemen Teknik Informatika Institut Teknologi Bandung," 2004.

[2] N. Sruthi, A. V. Sheetal, and V. Elamaran, "Spatial and spectral digital watermarking with robustness evaluation," 2014 Int. Conf. Comput. Power, Energy, Inf. Commun. ICCPEIC 2014, pp. 500-505, 2014.

[3] A. Furqan and M. Kumar, "Study and analysis of robust DWT-SVD domain based digital image watermarking technique using MATLAB," Proc. - 2015 IEEE Int. Conf. Comput. Intell. Commun. Technol. CICT 2015, pp. 638-644, 2015.

[4] Mulaab, "Teknik Watermarking dalam Domain Wavelet untuk Proteksi Kepemilikan pada Data Citra Medis," 2005.

[5] R. Choudhary and G. Parmar, "A robust image watermarking technique using 2-level 
discrete wavelet transform (DWT)," 2nd Int. Conf. Commun. Control Intell. Syst. CCIS 2016, no. Ll, pp. 120-124, 2017.

[6] A. Ustubioglu, G. Ulutas, and M. Ulutas, "DCT based image watermarking method with dynamic gain," 2015 38th Int. Conf. Telecommun. Signal Process. TSP 2015, pp. 550-554, 2015.

[7] E. Hidayat and E. Udayanti, "Hybrid Watermarking Citra Digital Menggunakan Teknik Dwt-Dct Dan Svd," Semantik, vol. 2011, no. Semantik, pp. 8-13, 2011.

[8] H. Lala, "Digital Image Watermarking using Discrete Wavelet Transform," Int. Res. J. Eng. Technol., vol. 04, no. 01, pp. 1682-1685, 2017.

[9] N. N. Kumar and S. Ramakrishna, "An Impressive Method to Get Better Peak Signal Noise Ratio (PSNR), Mean Square Error (MSE) Values Using Stationary Wavelet Transform (SWT)," Glob. J. Comput. Sci. Technol. Graph. Vis., vol. 12, no. 12, pp. 1-7, 2012.

[10] K. Masykuroh, I. I. Tritoasmoro, and A. Mulyana, "Analisis transmisi video pada kanal lossy dengan metode pengkodean wyner ziv," 2008.

[11] I. Setiani, U. Sunarya, and S. Aulia, "Modul Simulasi Teknik Watermarking Pada Citra Digital Menggunakan Metode Dwt Dan Dct the Simulation Module of Digital Image Watermark," vol. 3, no. 3, pp. 2133-2144, 2017.

[12] M. K. Reza, "Perancangan sistem watermarking pada citra digital menggunakan metode dct dan lsb," 2014. 